\title{
High Resolution Transmission Electron Microscopy Observations on Sintering Processes in $\mathrm{KNbO}_{3}$ Ceramics
}

\author{
Hwack Joo Lee*, Young Heon Kim, Hyun Ryu, Yang-Koo Cho, Sahn Nahm \\ Division of Industrial Metrology, Korea Research Institute of Standards and Science, Daejeon 34113, Korea \\ ${ }^{1}$ Department of Materials Science and Engineering, Korea University, Seoul 02841, Korea
}

*Correspondence to:

Lee $\mathrm{HJ}$,

Tel: +82-42-868-5321

Fax: +82-42-868-5032

E-mail: hjlee@ktiss.re.kr

Received July 17, 2017

Revised August 1, 2017

Accepted August 1, 2017

\begin{abstract}
A homogeneous $\mathrm{KNbO}_{3}(\mathrm{KN})$ phase was formed by sintering at $1,040^{\circ} \mathrm{C}$ for 1 hour, without formation of the $\mathrm{K}_{2} \mathrm{O}$-deficient secondary phase even though suffering the minor loss of $\mathrm{K}_{2} \mathrm{O}$. KN liquid phase was formed during sintering and abnormal grain growth occurred in this specimen. The detailed microstructural observations on KN during sintering were carried out using high resolution transmission electron microscopy. The ledged structures were found at the KN grain boundary and the abnormal grain growth was performed by the lateral migration of these ledges in the presence of the liquid phase. The liquid pockets were found in the KN grains. They have various external shapes mainly due to the kinetic factors. They have atomically flat interfaces with some ledges with one atomic height. The slight deficient $\mathrm{K}_{2} \mathrm{O}$ by evaporation might somewhat reduce the melting point of $\mathrm{KN}$ from the reported at $1,058^{\circ} \mathrm{C}$. The liquid pockets play an important role in supplying the liquid phase during the abnormal grain growth in the sintering process of KN ceramics.
\end{abstract}

Key Words: $\mathrm{KNbO}_{3}$, Lead-free piezoelectric ceramics, Liquid phase sintering, High resolution transmission electron microscopy, Liquid pockets

\section{INTRODUCTION}

Piezoelectric devices such as the ultrasonic motors, transformers, and actuators have received considerable attention due to their wide range of applications (Saito et al., 2004). Lead-zirconate-titanate $\left(\mathrm{Pb}(\mathrm{Zr}, \mathrm{Ti}) \mathrm{O}_{3}\right.$ or $\left.\mathrm{PZT}\right)$ based ceramics have been used for these devices because of their outstanding piezoelectric properties (Jaffe et al, 1971). However, PZT-based ceramics contain more than $60 \mathrm{wt} \%$ of $\mathrm{PbO}$, which causes serious environmental problems. There has been an increasing number of investigations on leadfree piezoelectric ceramics such as $\mathrm{BaTiO}_{3},\left(\mathrm{Bi}_{1 / 2} \mathrm{Na}_{1 / 2}\right) \mathrm{TiO}_{3}$, and $\left(\mathrm{Na}_{0.5} \mathrm{~K}_{0.5}\right) \mathrm{NbO}_{3}$ (NKN) (Rodel et al., 2009). Among these materials, NKN-based ceramics have attracted much attentions because of their high piezoelectric properties and high Curie temperature $\left(T_{c}\right)$ (Jarupoom et al., 2008). However, $\mathrm{NKN}$ ceramics decompose easily in water, and $\mathrm{Na}_{2} \mathrm{O}$ (or $\mathrm{K}_{2} \mathrm{O}$ ) evaporates during sintering at high temperatures $\left(>1,000^{\circ} \mathrm{C}\right)$. Therefore, it is very difficult to obtain dense NKN ceramics with homogeneous composition and reliable piezoelectric properties. To overcome this problem and to improve the piezoelectric properties, many investigations have been conducted on NKN-based solid solutions (Park et al., 2010). In particular, (1-x)NKN- $x \mathrm{Li}(\mathrm{Nb}, \mathrm{Ta}, \mathrm{Sb})$ solid solutions have been studied extensively because of their promising piezoelectric properties (Guo et al., 2004). The lowtemperature sintering of NKN-based ceramics has been also studied to prevent the evaporation of $\mathrm{Na}_{2} \mathrm{O}\left(\right.$ or $\left.\mathrm{K}_{2} \mathrm{O}\right)$ during sintering.

The $\mathrm{KNbO}_{3}(\mathrm{KN})$ ceramic could also be a candidate for leadfree piezoelectric ceramics since $\mathrm{KN}$ single crystal exhibited good piezoelectric properties and high $T_{c}$ (Nakamura et al., 2002). However, densification of the $\mathrm{KN}$ ceramics using the conventional solid-state method was very difficult because of the evaporation of $\mathrm{K}_{2} \mathrm{O}$ and formation of unwanted secondary phases (Birol et al., 2005). Therefore, special

(a) This is an open-access article distributed under the terms of the Creative Commons Attribution Non-Commercial License (http://creativecommons.org/licenses/by-nc/4.0) which permits unrestricted noncommercial use, distribution, and reproduction in any medium, provided the original work is properly cited.

Copyrights @ 2017 by Korean Society of Microscopy 
synthesis methods such as hot pressing (Jaeger and Egerton, 1962), sintering under an $\mathrm{O}_{2}$ atmosphere (Birol et al., 2005), and the addition of sintering aids (Kakimoto et al., 2004) were used to obtain dense and homogeneous KN ceramics. Two time calcination method with a cold isostatic press was also used to obtain dense $\mathrm{KN}$ ceramics via the conventional solidstate process (Hajime et al., 2007). However, the sintering temperature used in this method was $1,050^{\circ} \mathrm{C}$, which is very close to the melting temperature of $\mathrm{KN}$ ceramics $\left(1,058^{\circ} \mathrm{C}\right)$ (Irle et al., 1991).

Recently it was reported that the homogeneous $\mathrm{KN}$ phase was developed in the specimens sintered at $1,020^{\circ} \mathrm{C}$ and $1,040^{\circ} \mathrm{C}$ without the formation of the $\mathrm{K}_{2} \mathrm{O}$-deficient secondary phase and a small amount of the $\mathrm{KN}$ phase melted during sintering and assisted the densification and the abnormal grain growth (Kim et al., 2014). In present investigations, the detailed observations on the sintering mechanism of KN ceramics were carried out using high resolution transmission electron microscopy (HRTEM).

\section{MATERIALS AND METHODS}

Using conventional solid-state synthesis, $\mathrm{KN}$ ceramics were prepared. The oxide compounds of $\mathrm{K}_{2} \mathrm{CO}_{3}$, and $\mathrm{Nb}_{2} \mathrm{O}_{5}(>99 \%$, all from High Purity Chemicals, Japan) were mixed with zirconia balls in a plastic jar for 24 hours and then dried. The dried powders were calcined at $600^{\circ} \mathrm{C}$ for 4 hours and then heated at $1,000^{\circ} \mathrm{C}$ for 4 hours. The calcined $\mathrm{KN}$ powders were re-milled, dried, and pressed into discs under a pressure of $100 \mathrm{kgf} / \mathrm{cm}^{2}$ and sintered at $1,020^{\circ} \mathrm{C}$ and $1,040^{\circ} \mathrm{C}$ for various periods of time. The thickness and diameter of each specimen were 1.0 and $14.0 \mathrm{~mm}$, respectively. The detailed sample

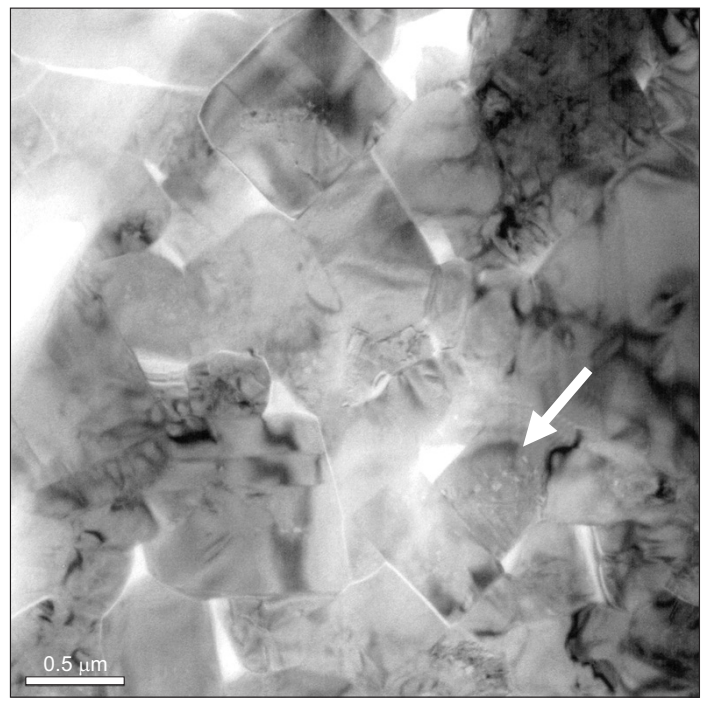

Fig. 1. Bright-field transmission electron microscopy micrograph of $\mathrm{KNbO}_{3}$ ceramics sintered at $1,040^{\circ} \mathrm{C}$ for 1 hour. preparations and their electrical properties are described elsewhere (Kim et al., 2014). The transmission electron microscopy (TEM) specimens were obtained by ultrasonic cutting into $3 \mathrm{~mm}$ diameter disks and then mechanically polishing to a thickness of $100 \mu \mathrm{m}$. Then the central parts of disk were further reduced to $10 \mu \mathrm{m}$ by mechanical dimpling. The perforation of the sample was carried out by precision Ar-ion milling (Gatan, 691) at an accelerating voltage of $3 \mathrm{kV}$. The specimens were investigated by FEI Technai (F30) field emission gun TEM operating at $300 \mathrm{kV}$ equipped with a postcolumn Gatan imaging filter (GIF Tridem) and scanning transmission electron microscopy unit.

\section{RESULTS AND DISCUSSION}

Fig. 1 shows a bright-field (BF) TEM image of KN ceramics sintered at $1,040^{\circ} \mathrm{C}$ for 1 hour. The grains have a flat square or rectangular boundaries rather than rounded shapes. These grains are cube or orthorhombic shapes in three dimensions when they are observed by scanning electron microscopy. There are several liquid triple junctions at the places where these grains are met. A stripe like ferroelectric domains is also seen inside the grains. Particularly in these ceramics, a certain grain has a separated group of small particles as indicated by an arrow. We refer to these particles as liquid pocket of KN and will describe them in detail.

Fig. 2 shows the HRTEM image of the grain boundaries of $\mathrm{KN}$ ceramics. This image is a reproduced enlarged image of Fig. 7(a) reported by Kim et al. (2014) for further detailed explanations. The lower grain has aligned with (001) plane parallel to the beam direction, which can be identified

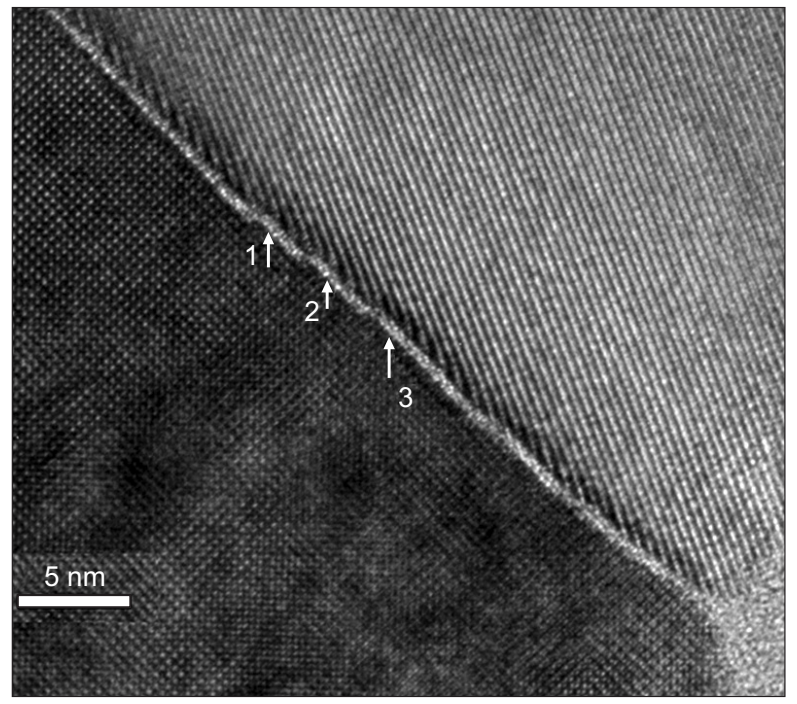

Fig. 2. High resolution transmission electron microscopy image of $\mathrm{KNbO}_{3}$ ceramics sintered at $1,040^{\circ} \mathrm{C}$ for 1 hour showing the ledged grain boundary structure. 
from the diffraction pattern with [001] zone axis. The grain boundary has the amorphous layers with the thickness of two atomic spacing. This layer was originally liquid phase at the sintering temperature and then transformed into amorphous solid phase when the specimens is cooled to room temperature after sintering. There are more than three ledged structures of about one atomic height present in this grain boundary as indicated by numbers. The intervals are approximately 3.0, 3.5 and $7.4 \mathrm{~nm}$ respectively. During the sintering, the grain growth might occur by the lateral migration of these ledges through the liquid phase which are present between them.

Fig. 3 shows a BF TEM images of KN demonstrating the KN liquid pockets formed inside the grain. These pockets are formed by the process of melting of $\mathrm{KN}$ at the sintering temperature. The melting starts at the surface of the crystal and then proceeds into the grain.

The liquid pockets have appeared to have somewhat a variety of shapes. The pockets as indicated by an arrow in Fig. $3 \mathrm{~A}$ shows the rectangular shape with the anisotropic shape with the aspect ratio of 1.75 , while the one which are located at the right side has the square shape with the ratio of 1.0. The pocket as indicated by an arrow in Fig. 3B has the shape of rounded ones. Since the crystal structure of $\mathrm{KN}$ at sintering temperature is simple cubic, it is expected that the liquid pocket wound have the square shape parallel to [001] direction. This implies that another kinetic factor might be involved in the formation of the liquid pockets. The high density of these liquid pockets is found in a certain $\mathrm{KN}$ grain as shown in Fig. 3C. The important fact is that when these liquid pockets are observed at room temperature by TEM, at least two processes are involved. One is the formation of liquid pocket by melting at sintering temperature and another is the recrystallization of the liquid phase by solidification process at the lower temperature during cooling to room temperature. When the liquid phase fails to recrystallize, it remains as the solid amorphous phase.

Kim et al. (2014) reported in their Fig. 6, the liquid pocket remained as amorphous. The composition of the liquid phase from EDX spectra, indicated that the ratio of $\mathrm{K}^{+}$and $\mathrm{Nb}^{5+}$
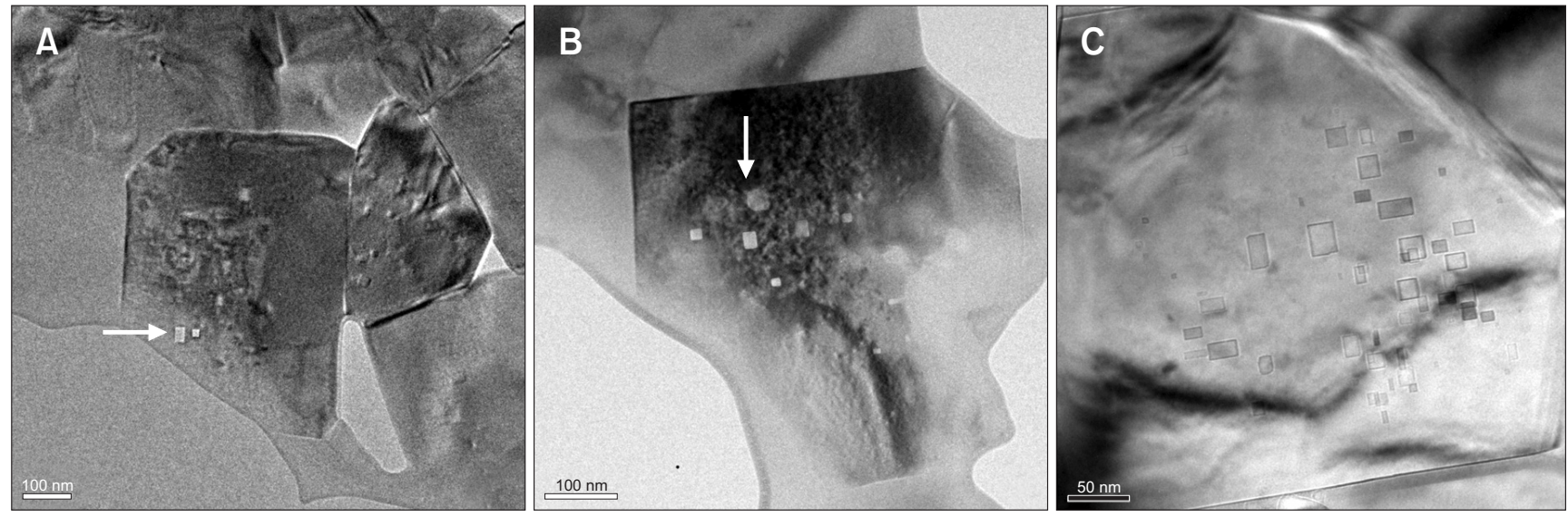

Fig. 3. Bright-field transmission electron microscopy micrographs of $\mathrm{KNbO}_{3}$ showing the various shapes of liquid pockets: (A) rectangular shape, (B) rounded one, and (C) high density of liquid pockets in a grain.
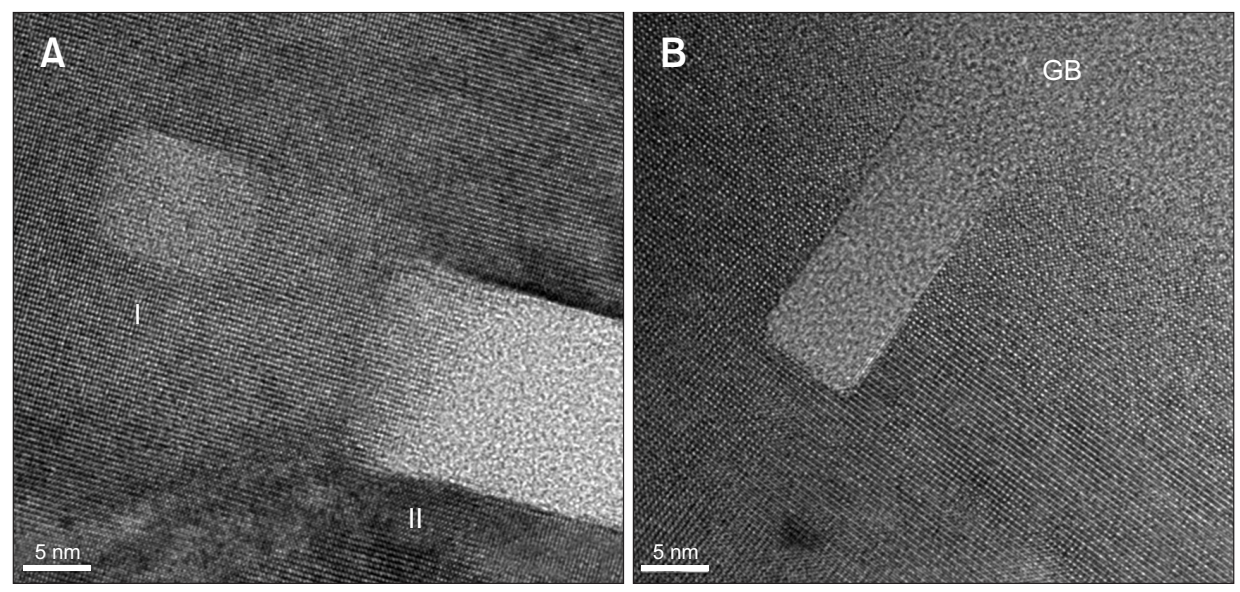

Fig. 4. High resolition transmission electron microscopy image of liquid pockets in a grain: (A) completely crystallized and partially crystallized (B) liquid pocket connected to grain boundary (GB). 


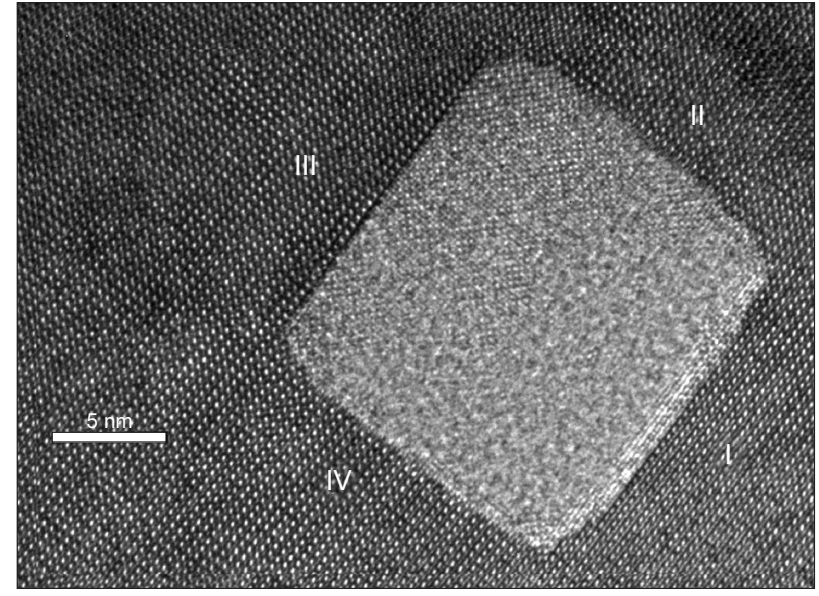

Fig. 5. High resolution tansmission electron microscopy image of highly magnified partially transformed liquid pocket in a $\mathrm{KNbO}_{3}$ grain.

ions existing in the liquid phase was 1.0:1.3. A similar result was also observed in the matrix phase.

Fig. 4A shows HRTEM images of other KN liquid pockets. The pocket numbered as I has transformed to crystal KN during the cooling to room temperature and the pocket II has partially transformed into the crystalline phase from the left side. The liquid pockets left the finger prints of their original boundary when they were melted during the sintering and were recrystallized during cooling to room temperature. The reason why the finger prints are remained is not clear; however, there might be slight misorientations between the parent phase and a newly forming phase, thus resulting a low angle interphase boundary between them. In Fig. 4B, the liquid pocket has joined the $\mathrm{KN}$ grain boundary. Then the pocket could supply the liquid phase to the grain boundaries and enhance the abnormal grain growth during sintering process. The both sides of the pocket consist of ledges.

Fig. 5 shows another HRTEM image of almost square liquid pocket. For convenience we designate the four interfaces as I, II, III, and IV respectively in counterclockwise direction from the bottom side of the right. The pocket has partially transformed mainly from both sides of II and III. It is difficult to identify the growth front mainly due to the weak contrast in the image.

It was found that the abnormal grain growth during the liquid phase sintering of ceramic materials was explained by the fact that the grains having atomically smooth interfaces grow by a two-dimensional nucleation mechanisms (Jo et al., 2006). These nuclei play an important role as growth ledges through the lateral migration of grain boundaries which are in contact with liquid phase. The mechanism seems to operate in $\mathrm{KN}$ grain boundaries as shown in Fig. 2.

The dissolution of KN crystal in the pocket during the sintering process and recrystallization during cooling to room temperature are governed by the lateral migration of these ledges. The density of these mobile ledges is the main factor in kinetics in dissolution and recrystallization. It was found that the lateral migration of growth ledges were common growth mechanism in the precipitation processes in metallic systems and especially the corners in the liquid pocket are possible sources for supplying the growth ledges (Aaronson et al., 1978). Therefore, the overall shapes of the liquid pockets were determined by these activities of these growth ledges as shown in Fig. 3.

The liquid pocket has started to be formed by the dissolution of $\mathrm{KN}$ through the screw dislocations at the surface of $\mathrm{KN}$ crystal. Probably a small amount of $\mathrm{K}_{2} \mathrm{O}$ could have evaporated during the sintering process, resulting in the formation of the $\mathrm{K}_{2} \mathrm{O}$-deficient $\mathrm{KN}$ ceramics further lowers the melting point of $\mathrm{KN}$ from $1,058^{\circ} \mathrm{C}$ (Irle et al., 1991).

\section{CONCLUSIONS}

A homogeneous $\mathrm{KN}$ phase was developed in the specimens sintered at $1,040^{\circ} \mathrm{C}$ without the formation of the $\mathrm{K}_{2} \mathrm{O}$ deficient secondary phase. It was found that a small amount of the $\mathrm{KN}$ phase has melted during the sintering process and assisted the densification and abnormal grain growth. The ledged structures were found at the $\mathrm{KN}$ grain boundary and the abnormal grain growth was performed by the lateral migration of these ledges in the presence of the liquid phase. The liquid pockets were found in the $\mathrm{KN}$ grains. They have various external shapes mainly due to the kinetic factors. They have atomically flat interfaces with some ledges with one atomic height. The slight deficient $\mathrm{K}_{2} \mathrm{O}$ might slightly reduce the melting point of $\mathrm{KN}$ from the reported at $1,058^{\circ} \mathrm{C}$ (Irle et al., 1991). The liquid pockets play an important role in supplying the liquid phase during the abnormal grain growth in the sintering process of $\mathrm{KN}$ ceramics.

\section{CONFLICT OF INTEREST}

No potential conflict of interest relevant to this article was reported.

\section{ACKNOWLEDGMENTS}

This work was carried out through the internal basic research program in KRISS (Korea Research Institute of Standards and Science) and one of the authors (S. Nahm) was partially supported by the Future Rail Technology Development Project (former KAIA, KICTEP) grant funded by the Ministry of Land, Transport and Maritime Affairs, Republic of Korea (development of piezoelectric harvesting system for application of train). 


\section{REFERENCES}

Aaronson H I, Lee J K, and Russell K C (1978) Diffusional nucleation and growth. In: Precipitation Processes in Solids, eds. Russell K C and Aaronson H I, pp. 31-86, (AIME, New York).

Birol H, Damjanovic D, and Setter N (2005) Preparation and characterization of $\mathrm{KNbO}_{3}$ ceramics. J. Am. Ceram. Soc. 88, 1754 1759.

Guo Y, Kakimoto K, and Ohsato H (2004) Dielectric and piezoelectric properties of lead-free $\left(\mathrm{Na}_{0.5} \mathrm{~K}_{0.5}\right) \mathrm{NbO}_{3}-\mathrm{SrTiO}_{3}$ ceramics. Solid State Commun. 129, 279-284.

Hajime N, Kenji M, Tadayuki H, Yuji H, and Tadashi T (2007) Fabrication and electrical properties of potassium niobate ferroelectric ceramics. Jpn. J. Appl. Phys. 46, 7084-7088.

Irle E., Blachnik R, and Gather $\mathrm{B}$ (1991) The phase diagrams of $\mathrm{Na}_{2} \mathrm{O}$ and $\mathrm{K}_{2} \mathrm{O}$ with $\mathrm{Nb}_{2} \mathrm{O}_{5}$ and the ternary system niobium $\mathrm{Nb}_{2} \mathrm{O}_{5}-\mathrm{Na}_{2} \mathrm{O}-\mathrm{Yb}_{2} \mathrm{O}_{3}$. Thermochim. Acta 179, 157-169.

Jaeger R E and Egerton L (1962) Hot pressing potassium-sodium niobates. J. Am. Ceram. Soc. 45, 209-213.

Jaffe B, Cook W. R, and Jaffe H (1971) Piezoelectric Ceramics. pp. 192 271, (Academic, New York).

Jarupoom P, Pengpat K, Eitssayeam S, Intatha U, Rujijanagul G, and Tunkasiri T (2008) Structures and properties of lead-free NKN piezoelectric ceramics. Ferroelectr. Lett. 35, 119-127.

Jo W, Kim D Y, and Hwang N M (2006) Effect of interface structure on the microstructural evolution of ceramics. J. Am. Ceram Soc. 89, 2369 2380.

Kakimoto K, Masuda I, and Ohsato H (2004) Solid-solution structure and piezoelectric property of $\mathrm{KNbO}_{3}$ ceramics doped with small amounts of elements. Jpn. J. Appl. Phys. 43, 6706-6710.

Kim D H, Joung M R, Seo I T, Hur J, Kim J H, Kim B Y, Lee H J, and Nahm $S$ (2014) Influence of sintering conditions on piezoelectric properties of $\mathrm{KNbO}_{3}$ ceramics, J. Euro Ceram. Soc. 34, 4193-4200.

Nakamura K, Tokiwa T, and Kawamura Y (2002) Domain structures in $\mathrm{KNbO}_{3}$ crystals and their piezoelectric properties. J. Appl. Phys. 91 9272-9276.

Park H Y, Seo I T, Choi J H, Nahm S, and Lee H G (2010) Low temperature sintering and piezoelectric properties of $\left(\mathrm{Na}_{0.5} \mathrm{~K}_{0.5}\right) \mathrm{NbO}_{3}$ lead-free piezoelectric ceramics. J. Am. Ceram. Soc. 93, 36-39.

Rodel J, Jo K W, Seifert T P, Anton E M, and Granzow T, Damjanovic D (2009) Perspective on the Development of Lead-free Piezoceramics. J. Am. Ceram. Soc. 92, 1153-1177.

Saito Y, Takao H, Tani T, Nonoyama T, Takatori K, Homma T, Nagaya T, and Nakamura M (2004) Lead-free piezoceramics. Nature 432, 84-87. 